\title{
sGC $\alpha, \beta$, attenuates cardiac dysfunction and mortality in murine inflammatory shock models
}

Emmanuel S Buys*1,2, Anje Cauwels ${ }^{3,4}$, Michael J Raher ${ }^{1,2}$, Jonathan J Passeri ${ }^{5}$, Ion Hobai ${ }^{1}$, Sharon M Cawley ${ }^{2}$, Kristen M Rauwerdink ${ }^{1}$, Helene Thibault ${ }^{5}$, Patrick Y Sips ${ }^{1}$, Robrecht Thoonen ${ }^{3,4}$, Marielle ScherrerCrosbie $^{2,5}$, Fumito Ichinose ${ }^{1}$, Peter Brouckaert ${ }^{3,4}$ and Kenneth D Bloch ${ }^{1,2}$

Address: ${ }^{1}$ Anesthesia Center for Critical Care Research, Department of Anesthesia and Critical Care, Massachusetts General Hospital, Harvard Medical School, Boston, MA, USA, ${ }^{2}$ Cardiovascular Research Center, Massachusetts General Hospital, Harvard Medical School, Charlestown, MA, USA, ${ }^{3}$ Department of Medical Molecular Biology, Flanders Institute for Biotechnology (VIB), Ghent, Belgium, ${ }^{4}$ Department of Molecular Biology, Ghent University, Ghent, Belgium and ${ }^{5}$ Cardiac Ultrasound Laboratory, Cardiology Division, Department of Medicine, Massachusetts General Hospital, Harvard Medical School, Boston, MA, USA

Email: Emmanuel S Buys* - ebuys@partners.org

* Corresponding author

from 4th International Conference of cGMP Generators, Effectors and Therapeutic Implications

Regensburg, Germany. 19-21 June 2009

Published: II August 2009

BMC Pharmacology 2009, 9(Supp| I):P5 doi:I0.I |86/I47|-22 I0-9-SI-P5

This abstract is available from: http://www.biomedcentral.com//47I-22I0/9/SI/P5

(c) 2009 Buys et al; licensee BioMed Central Ltd.

\section{Background}

Altered cGMP signaling has been implicated in myocardial depression, morbidity, and mortality associated with sepsis. Previous studies, using inhibitors of soluble guanylate cyclase (sGC), suggested that cGMP generated by sGC contributed to the cardiac dysfunction and mortality associated with sepsis. We used mice deficient in $\mathrm{sGC} \alpha_{1}$ (sGCa ${ }^{-1-m i c e)}$ to unequivocally determine the role of $\mathrm{sGC} \alpha_{1} \beta_{1}$ in the development of cardiac dysfunction and death associated with two models of inflammatory shock: endotoxin-induced and TNF-induced shock.

\section{Results}

At baseline, echocardiographic assessment and invasive hemodynamic measurements of left ventricular (LV) dimensions and function did not differ between WT and $\mathrm{sGC}_{1}-$-mice on the $\mathrm{C} 57 \mathrm{BL} / 6$ background $\left(\mathrm{sGC}_{1}{ }^{-/-\mathrm{B} 6}\right.$ mice). Fourteen hours after a challenge with endotoxin, cardiac dysfunction was more pronounced in $\mathrm{sGC}_{1}{ }^{-/-\mathrm{B} 6}$ mice than in WT mice, as assessed using echocardiographic and hemodynamic indices of LV function. Similarly, $\mathrm{Ca}^{2+}$ handling and cell shortening were impaired to a greater extent in cardiac myocytes isolated from sGC $\alpha_{1}^{-1}$
-B6 mice than in those from WT mice after a challenge with endotoxin. Importantly, morbidity and mortality associated with inflammatory shock induced either by endotoxin or TNF were increased in $\mathrm{sGC} \alpha_{1}^{-/-B 6}$ mice as compared to WT mice.

\section{Conclusion}

Together, these findings suggest that cGMP generated by sGC $\alpha_{1} \beta_{1}$ protects against cardiac dysfunction and mortality in murine models of inflammatory shock. 